\title{
Two components of responding in Pavlovian lick suppression
}

\author{
Jeremie Jozefowiez • James E. Witnauer • \\ Ralph R. Miller
}

Published online: 4 January 2011

(C) Psychonomic Society, Inc. 2010

\begin{abstract}
The present research examined the temporal distribution of responding in a lick suppression paradigm. In Experiment 1, rats were trained with either a 30- or a 120 -s conditioned stimulus (CS), which was followed either by a footshock (unconditioned stimulus [US]) or nothing. Licking during the CS was suppressed only in the former condition. Suppression was more pronounced early in the CS. In Experiment 2, rats were exposed to two 30-s or two 120 -s CSs, with delivery of the shock being contingent on CS1 for half of the animals and on CS2 for the other half. For both the paired and the unpaired conditions, suppression at the beginning of CS1 was observed for all the groups. By discounting the possibility of generalization between CS1 and CS2, it appears that this initial suppression was not a conditioned response to the CS, but an unconditioned one due to mere exposure to the shock US.
\end{abstract}

Keywords Fear conditioning · Lick suppression .

Conditioned responding · Unconditioned responding .

Pseudoconditioning

\footnotetext{
J. Jozefowiez $(\bowtie)$

Escola de Psicologia,

Universidade do Minho,

Campus de Gualtar,

4710 - 057 Braga, Portugal

e-mail: jeremie@psi.uminho.pt

J. E. Witnauer

Department of Psychology,

State University of New York at Brockport,

Brockport, NY, USA

R. R. Miller

Department of Psychology,

State University of New York at Binghamton,

Binghamton, NY, USA
}

If an appetitive unconditioned stimulus (US) is delivered after a fixed amount of time following the onset of a conditioned stimulus (CS), the distribution of conditioned responding across the CS duration is usually tuned to the CS-US interval, a phenomenon labeled inhibition of delay (see Church, 2002, for a recent review). Such temporally regulated behavior has also been observed, although with more difficulty, in aversively motivated Pavlovian paradigms such as conditioned barpress suppression (Estes \& Skinner, 1941), a widely used procedure in which fear triggered by a CS that was previously paired with a footshock US is assessed by measuring the degree to which the CS disrupts baseline barpressing for food or water according to a variable-interval (VI) schedule of reinforcement (see Hammond \& Maser, 1970; Hendry \& Van-Toller, 1965; Holmes, Jackson, \& Byrum 1971; Labarbera \& Church, 1974; Libby \& Church, 1975; Rosas \& Alonso, 1996, 1997a, 1997b; Schachtman, Channell, \& Hall 1987; Zielinski, 1966).

Reports by Miller and his colleagues (e.g., Amundson \& Miller, 2008; Arcediano, Escobar, \& Miller 2003, 2005; Barnet, Cole, \& Miller 1997; Blaisdell, Denniston, \& Miller 1998; Cole, Barnet, \& Miller 1995) also have suggested that temporal learning occurs in conditioned lick suppression, a procedure almost identical to conditioned barpress suppression, except for the target response (licking of a water spout instead of barpressing) and the schedule of reinforcement for that response (continuous reinforcement vs. VI). However, the way temporal learning was assessed by Miller and his colleagues differs considerably from the way it has been assessed in most barpress suppression experiments. In the latter, the temporal distribution of responding during the $\mathrm{CS}$ has been recorded in order to assess whether the level of suppression increases with time in the CS (inhibition of delay), which is considered proof 
that the animal has learned the CS-US interval. Miller and his colleagues did not report the temporal distribution of responding in their studies. Rather, they based their conclusions on the time taken by a rat to complete 5 consecutive seconds of drinking in the presence of the CS (i.e., the overall strength of suppression, rather than the change in suppression across the CS). Moreover, because their aim was to test the temporal-coding hypothesis (e.g., Savastano \& Miller, 1998), they inferred temporal learning by comparing the strength of the conditioned response (CR) after pairings of a second-order cue (S2) with a first-order CS (S1) with different S1-S2 and S1-US temporal arrangements. Miller and his colleagues' use of trace conditioning within second-order conditioning and sensory preconditioning makes the comparison with the barpress suppression studies even more difficult, because the latter used delay conditioning. Hence, the present study recorded this distribution in a lick suppression procedure using a delay conditioning paradigm.

\section{Experiment 1}

Experiment 1 examined the temporal distribution of lick suppression. We employed two different stimulus durations (30 and $120 \mathrm{~s}$ ). The procedure used only first-order delay conditioning (rather than sensory preconditioning or second-order conditioning) to facilitate comparison with the data from barpress suppression and appetitive studies. We asked whether timed behavior would be observed for either stimulus duration.

\section{Method}

Subjects Subjects were 36 female and 36 male SpragueDawley, experimentally naive, young adult rats, bred in our colony. At the start of the experiment, body weights were between 167 and $235 \mathrm{~g}$ for the females and 236 and $332 \mathrm{~g}$ for the males. Subjects were individually housed and maintained on a 16:8-hr light:dark cycle with experimental sessions occurring roughly midway through the light portion. All the subjects were handled for $30 \mathrm{~s}$ three times per week from weaning until the initiation of the study. Subjects had free access to food in their home cages. One week prior to initiation of the experiment, water availability was progressively reduced to $20 \mathrm{~min}$ per day, given within $2 \mathrm{hr}$ following the end of any daily treatment.

Apparatus Six identical copies of each of two different types of experimental chambers were used. Chamber Rectangular (R) was a clear, Plexiglas, rectilinear chamber, measuring $22.75 \times 8.25 \times 13.00 \mathrm{~cm}($ length $\times$ width $\times$ height $)$. The floor was constructed of 0.5 -cm-diameter stainless steel rods, spaced $1.5 \mathrm{~cm}$ apart, center to center. The rods were connected by NE-2 neon bulbs that allowed a constantcurrent footshock to be delivered by means of a high voltage AC circuit in series with a $1.0-\mathrm{M} \Omega$ resistor. Each copy of Chamber $\mathrm{R}$ was housed in a separate light- and soundattenuating environmental isolation chest, which was dimly illuminated by a 2-W (nominal at 120 VAC) incandescent bulb driven at $80 \mathrm{VAC}$. The houselight was mounted on the ceiling of the environmental chest, approximately $26 \mathrm{~cm}$ from the center of the experimental chamber.

Chamber V-shaped (V) was a $25.5-\mathrm{cm}$-long box in a truncated-V shape $(28.0 \mathrm{~cm}$ high, $21.0 \mathrm{~cm}$ wide at the top, $5.25 \mathrm{~cm}$ wide at the bottom). The floor and sides were constructed of stainless steel sheets, and the ceiling was constructed of clear Plexiglas. The floor of each chamber consisted of two parallel metal plates, each $2.0 \mathrm{~cm}$ wide, with a $1.25-\mathrm{cm}$ gap between them. Each V-shaped chamber was housed in its own environmental isolation chest, which was dimly illuminated by a 7-W (nominal at 120 VAC) incandescent houselight driven at $80 \mathrm{VAC}$, mounted on an inside wall of the environmental chest, approximately $30 \mathrm{~cm}$ from the center of the experimental chamber. The light entering the animal chamber was primarily that reflected from the roof of the environmental chest, which was composed of white insulating material. The light intensities in the two types of chambers were approximately equal due to the differences in opaqueness of the walls in Chambers $\mathrm{R}$ and $\mathrm{V}$.

Each chamber ( $R$ and $V$ ) could be equipped with a water-filled lick tube that extended $1 \mathrm{~cm}$ from the rear of a cylindrical niche, $4.5 \mathrm{~cm}$ in diameter, left-right centered in one short wall, with its axis perpendicular to the wall, and positioned with its center $2.5 \mathrm{~cm}$ above the floor of the chamber. Each niche had a horizontal infrared photobeam traversing it parallel to the wall on which the niche was mounted, $1 \mathrm{~cm}$ in front of the lick tube. In order to drink from the tube, subjects had to insert their heads into the niche, thereby breaking the infrared photobeam. Thus, we could record when subjects had their heads in the niche with the water tube. Ordinarily, they did this only when they were drinking.

The CS was a complex tone composed of two frequencies, 3000 and $3200 \mathrm{~Hz}$, presented simultaneously. It was delivered $6 \mathrm{~dB}$ (C scale) above background by a speaker on the inside wall of the chamber. Ventilation fans in each chest provided a constant background noise of $74 \mathrm{~dB}$ (C scale). The US consisted of a $0.3-\mathrm{s}, 0.75-\mathrm{mA}$ footshock, which co-terminated with the CS.

Procedure The experimental design is summarized in Table 1. Subjects were randomly assigned to one of six groups ( $n \mathrm{~s}=12$, counterbalanced for sex and chamber): 30 s-US，30-s-no-US，120-s-US，120-s-no-US，30-s-US2, and 120 -s-US2. The 30-s-US, 30-s-no-US, 120-s-US, and 
Table 1 Design of Experiment 1

\begin{tabular}{lll}
\hline Group & Training & Data Recorded Using \\
\hline 30 -s-US & 30 -s X+ & 2.5 -s bins \\
30 -s-no-US & 30 -s X- & 2.5 -s bins \\
120 -s-US & 120 -s X+ & 10 -s bins \\
120 -s-no-US & 120 -s X- & 10 -s bins \\
$30-$-US2 & 30 -s X+ & 2.5 -s bins \\
$120-$-US2 & $120-\mathrm{s} \mathrm{X}+$ & 2.5 -s bins \\
\hline
\end{tabular}

$\mathrm{X}$ was a complex tone. + indicates footshock at the end of the CS; indicates nonreinforcement. After 44 and 88 trials, restoration of baseline drinking occurred followed by one CS test trial. To keep the $\mathrm{C} / \mathrm{T}$ ratio constant, the average ITI was $10 \mathrm{~min}$ in the groups exposed to a 30 -s stimulus and $40 \mathrm{~min}$ in the groups exposed to a 120 -s stimulus

120-s-no-US groups formed a 2 (CS duration: 30 vs. 120 s) $\times 2$ (CS-US pairing: yes vs. no) factorial design. The two no-US control groups attempted to control for any variation in licking due to processes such as an orienting response to the CS, which could account for a suppression of responding at the beginning of the CS, or satiation, which, in turn, could explain any decrease in responding at the end of the CS (see Experiment 2 for alternative control strategies). Because of the limitations of our recording apparatus, the data were aggregated into temporal bins during the test trial. Thus, test data in these groups were recorded using 2.5-s bins for the 30-s groups and 10-s bins for the 120-s groups, so that we could look at the temporal pattern of responding during the whole CS for both CS durations. Testing in these groups assumed that the delay to drinking onset would be a scalar function of the duration of the test cue. However, this would not allow us to ascertain whether there was any effect of CS duration in real time. Consequently, we included the $30-\mathrm{s}-\mathrm{US} 2$ and $120-\mathrm{s}-\mathrm{US} 2$ groups, which were, in training, exact replications of the $30 \mathrm{~s}-\mathrm{US}$ and 120 -s-US groups, respectively. The test data for both of these groups were recorded using 2.5-s bins, thereby allowing a comparison of performance in real time. Note that this made the 30 -s-US2 group an exact replication of the 30 -s-US group, thereby allowing us to assess the reliability of our results in this condition.

Subjects were acclimated to and tested in one context (the test context) and were exposed to target training in a distinctly different context (the training context). This was done to reduce the impact of fear triggered by the training context on performance during testing. Those contexts were created by using one type of chamber ( $\mathrm{R}$ or $\mathrm{V}$, counterbalanced within group) to train a rat and the other type of chamber to test it.

On Days 1 and 2, all the subjects were systematically acclimated to the test context during daily 60 -min sessions. During the acclimation sessions, lick tubes were present.
Acclimation served to reduce unconditioned fear of the test context during subsequent reacclimation and testing.

During conditioning (Days 3-14), which took place in the training context over 11 consecutive days, the animals received four daily presentations of the CS. The stimulus was $30 \mathrm{~s}$ long in the 30 -s condition and $120 \mathrm{~s}$ long in the 120-s condition, with the footshock being delivered during the last $0.3 \mathrm{~s}$ of the CS in the US and US2 conditions and with the footshock omitted in the no-US condition. The mean $\mathrm{C} / \mathrm{T}$ ratio (the ratio between the inter-trial interval and CS duration) was held constant across CS duration (Gibbon \& Balsam, 1981). For the 30-s groups, the mean intertrial interval (ITI), onset to onset, was 10 min (varying among 5 , 7,13 , and $15 \mathrm{~min}$ ), with a mean of $5 \mathrm{~min}$ from the moment the rats were placed in the chamber to the presentation of the first stimulus. The mean session duration was $45 \mathrm{~min}$. For the 120 -s condition, the mean ITI was 40 min (varying among $20,28,52$, and $60 \mathrm{~min}$ ), with a mean of $20 \mathrm{~min}$ from the moment the rats were put in the chamber to the presentation of the first stimulus. The mean session duration was $3 \mathrm{hr}$. Within these constraints, the times of CS presentation during a session were determined randomly each day. No lick tube was present on these days.

After the completion of training, all the subjects were reacclimated over the next 2 days to the test context. As in the acclimation stage, the rats were placed in the chamber for $1 \mathrm{hr}$, with free access to water. On the day after completion of reacclimation, the rats were tested. Each rat was placed in the test context. After it had licked for 5 cumulative seconds, licking was recorded for $5 \mathrm{~s}$, following which the CS was presented for $30 \mathrm{~s}$ in the 30 -s groups and for $120 \mathrm{~s}$ in the 120 -s groups.

\section{Results}

Following the convention of our laboratory, rats that failed to complete 5 cumulative seconds of drinking within $1 \mathrm{~min}$ of being placed in the test were scheduled to be excluded from the analysis for exhibiting abnormal fear of the test context. In practice, no rat met this criterion. These pre-CS times to complete 5 cumulative seconds of drinking were $\log$ (base 10) transformed to improve within-group normality, thereby better meeting the requirements of parametric statistics. To assess whether there was any baseline difference between the groups before the CS was presented, an analysis of variance (ANOVA) was conducted on these log times using CS duration (30 vs. $120 \mathrm{~s}$ ) and CS-US pairing (yes vs. no) as factors in analyzing the data for Groups 30s-US, 30-s-no-US, 120-s-US, and 120-s-no-US. A separate ANOVA was conducted using CS duration (30 vs. $120 \mathrm{~s}$ ) as factors for Groups 30-s-US2 and 120-s-US2. Neither of these analyses yielded any significant effects (all 
$p \mathrm{~s}>.05)$, suggesting the absence of appreciable pre-CS differences in lick rates.

Figure 1 depicts the suppression ratio during testing as a function of group and relative time in the CS. The suppression ratio in bin $j$ for each rat was computed, with $C S_{j}$ being the rate of licking for a rat for bin number $\mathrm{j}$ during the $\mathrm{CS}$, and preCS being the lick rate during the last $5 \mathrm{~s}$ before the CS presentation:

$s r(j)=\frac{C S_{j}}{C S_{j}+p r e C S}$.

Each point on the graph represents a 2.5 -s bin for the rats trained with a 30-s CS and a 10-s bin for the rats trained with a 120 -s CS. One rat in the 30-s-US group failed to respond during the $5 \mathrm{~s}$ preceding the CS presentation used as an estimation of baseline responding in the absence of the CS and, hence, was excluded from the analysis. The amount of suppression was negligible (see the top panel of Fig. 1) among subjects that did not receive the US; the rate of licking during the CS remained constant at baseline level. In contrast, the two paired groups suppressed responding immediately upon
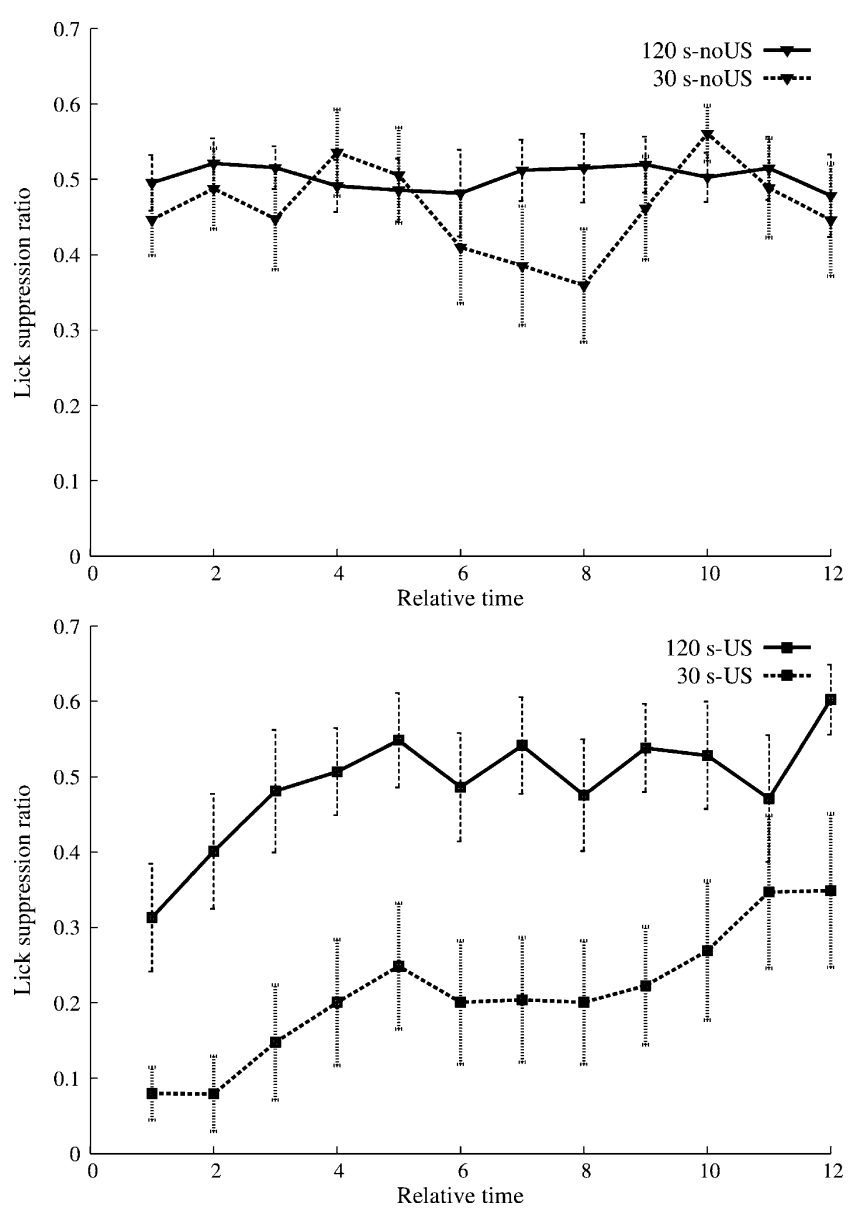

Fig. 1 Lick suppression ratio during the CS as a function of relative time, and condition for Groups 30-s-US, 120-s-US, 30-s-no-US, and 120 -s-no-US in Experiment 1. Bars represents standard errors
CS onset but quickly recovered (see the bottom panel of Fig. 1), with a greater degree of initial suppression for the rats trained with the 30 -s CS. Recovery was complete in the 120 -s group (the rate of licking reached a level equal to that of the control groups), whereas the rate of licking remained partially suppressed in the 30 -s-US group.

Statistical analysis confirmed these impressions. An alpha value of .05 was used for all analyses. A mixed design ANOVA using relative time in the CS, CS duration, and CS-US pairing as factors yielded an effect of relative time in the CS, $F(11,473)=2.65, p<.01$, CS duration, $F(1,43)=12.84, p<.01$, and CS-US pairing, $F(1,43)=8.51, p<.01$, as well as significant interactions between relative time in the CS and CS-US pairing, $F(11$, $473)=2.45, p<.01$, and between CS duration and CS-US pairing, $F(1,43)=7.04, p<.01$. The former interaction is the critical one. An analysis of the simple effects revealed no effect of time in the CS for the groups not exposed to the US, $\mathrm{F}(11,253)=0.74, p>.05$, whereas a strong effect of time in the CS was detected for the groups exposed to the US, $\mathrm{F}(11,242)=4.11, p<.01$.

Figure 2 depicts suppression ratio as a function of time in the CS during the first $30 \mathrm{~s}$ of the CS for Groups 120-sUS2 and 30-s-US2. Bins of $2.5 \mathrm{~s}$ were used for both groups. These groups replicated the pattern of data shown in Fig. 1. Responding was suppressed at the beginning of the CS but quickly recovered. Although the 30-s group initially suppressed more than the 120-s group, the fact that the two curves are almost parallel to each other suggests that responding recovers at the same rate in both groups. A mixed design ANOVA, using time in the CS and CS duration as factors, yielded an effect of time, $F(11,242)=$ $7.01, p<.01$, and of CS duration, $\mathrm{F}(1,22)=6.18, p<.01$. There was no interaction between time and CS duration.

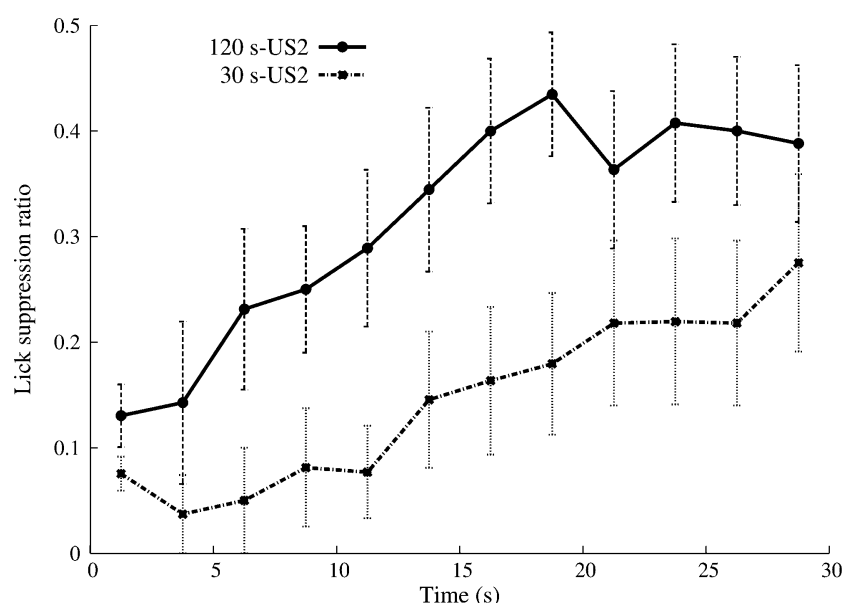

Fig. 2 Lick suppression ratio as a function of absolute time during the first $30 \mathrm{~s}$ of the CS as a function of number of trials and condition for Groups 30-s-US2 and 120-s-US2 in Experiment 1. Bars represents standard errors 
The failure to detect an interaction between CS duration during training and test bin reveals that the temporal distribution of suppression did not depend on the duration of the training CS, which constitutes a failure to replicate both inhibition of delay and the scalar relationship between training CS duration and conditioned responding.

\section{Discussion}

Experiment 1 examined the temporal distribution of lick suppression. We did not observe inhibition of delay (more suppression at the end of the CS than at the beginning), which usually indicates that subjects have learned the CS-US interval. Instead, the rats exhibited a reactive pattern, suppressing more at the beginning of the CS than at the end. This pattern was observed only among subjects that received the US. Initial suppression was larger in the group trained with a 30-s CS, and their suppression ratios never caught up with 120-s CS group. The rate of response recovery seemed identical in the two groups. Overall, greater suppression in the 30-s groups occurred across the entire test.

Such a reactive pattern had been reported at least twice before. The first time was by Rescorla (1968). After training rats offline in a barpress suppression procedure, he tested repeatedly in extinction. He observed that the level of suppression decreased during the 120 -s CS, even though, on the first day of extinction, suppression was almost complete during the entire CS. A reactive temporal distribution of responding was reported more recently by Bouton, Frohardt, Sunsay, Waddell, and Morris (2008). In their Experiment 3, it was observed with a 60-s CS trained online in a barpress procedure. Interestingly, it was observed even when the shock was delivered randomly during the CS, rather than at the end of it, indicating that this pattern is not sensitive to the CS-US interval.

If we note $R(t)$ as the level of suppression $t$ units of time into the CS, one way to make sense of the present data is to assume that $R(t)=f(\mathrm{CS}, \mathrm{US}, \mathrm{CS}-\mathrm{US})+g(t) . f(\mathrm{CS}, \mathrm{US}, \mathrm{CS}-$ US) here is the level of fear triggered by the CS: It does not vary through time and is a function of the CS, the US, and the CS-US contingency. Even though Gibbon and Balsam (1981) argued that there should not be any CS duration effect when the $\mathrm{C} / \mathrm{T}$ ratio is held constant, we can conclude that $f(\mathrm{CS}, \mathrm{US}, \mathrm{CS}-\mathrm{US})$ was lower for the 120 -s CS group than for the 30-s CS group, thereby explaining the higher level of suppression in the former group. The value of $g(t)$, which is a time-varying component, decreases with time. Since this component was not observed in the control groups, it is a function either of US exposure or of CS-US contingency. In the latter case, it would be a genuine fear $\mathrm{CR}$ to the $\mathrm{CS}$, although it would be a paradoxical one, because it would mean that the animals are more afraid of the CS at its onset, when the probability of US delivery was lowest, than at its termination, when US delivery was imminent. In the former case, it would reflect a change in the processing of stimuli induced by the mere exposure to the US (i.e., sensitization, reduced habituation, or both). Experiment 2 was designed to distinguish between these hypotheses by comparing the performance of two groups equally exposed to the US, but with only one group experiencing the shock contingent upon the CS.

\section{Experiment 2}

Experiment 2 sought to determine whether the reactive pattern observed in Experiment 1 reflected a CR to the CS or an unconditioned change in responding to the CS due to the mere exposure to the US. Because Experiment 1 controlled for exposure to the CS, a nonassociative account of the reactive pattern could be based only on variations in unconditioned responding that were driven by differential exposure to the US. Such an effect might be expected if exposure to the US resulted in sensitization or reduced habituation to the CS. Thus, in Experiment 2, all the subjects received identical US exposure. All the subjects received training with two auditory stimuli, $\mathrm{X}$ and $\mathrm{Y}$. Paired groups received $\mathrm{X}-\mathrm{US}$ pairings interspersed among Y-alone presentations. Unpaired groups received Y-US pairings interspersed among X-alone presentations. All the subjects were then tested on $\mathrm{X}$. Because the paired and unpaired groups were matched on exposure to both the CS and the US, unconditioned responding should not have been able to contribute to any difference between the two conditions.

\section{Method}

Subjects and apparatus Subjects were 24 female and 24 male Sprague-Dawley, experimentally naive, young adult rats, bred in our colony. Body weights were between 236 and $330 \mathrm{~g}$ for the males and 167 and $242 \mathrm{~g}$ for the females. Animal maintenance was the same as in Experiment 1. The apparatus was the same as that in Experiment 1, except that, in addition to the tone, a white noise could be presented by the speaker on the inside wall of the chamber.

Procedure Table 2 summarizes the design for Experiment 2. Subjects were randomly assigned to one of four groups: 30 s-paired, 120-s-paired, 30-s-unpaired, 120-s-unpaired ( $n s=$ 12). Sex, boxes, and the physical identity of $X$ and $Y$ (tone or white noise) were counterbalanced within groups. Counterbalancing of the nature of stimuli $\mathrm{X}$ and $\mathrm{Y}$ was done to equate the associative histories of the contexts and the US as much as possible.

As in Experiment 1, subjects were acclimated to and tested in one context (test) and were exposed to target 
training in a distinctly different context (training). On Days $1-3$, all the subjects were acclimated to the test context during daily 60-min sessions. During the acclimation sessions, lick tubes were present.

During conditioning, which took place in the training context on Days 4-10 with no lick tube present, animals received daily sessions consisting of four presentations each of the $\mathrm{X}$ and $\mathrm{Y}$ stimuli, and of the US. The shock was delivered during the last $0.3 \mathrm{~s}$ of the stimulus on which it was contingent (stimulus $\mathrm{X}$ for the paired groups, stimulus $\mathrm{Y}$ for the unpaired groups). The stimuli were $30 \mathrm{~s}$ long in the 30 -s groups and $120 \mathrm{~s}$ long in the 120 -s groups. The average $\mathrm{C} / \mathrm{T}$ ratio was held constant across the two CS duration conditions. Thus, the average ITI, onset to onset, was $5 \mathrm{~min}$ in the 30 -s groups and $20 \mathrm{~min}$ in the 120 -s groups, with the average time between the moment the rats were put in the cage and the moment the first stimulus was presented equaling the average ITI. The average total session duration was $45 \mathrm{~min}$ for the 30 -s groups and $180 \mathrm{~min}$ for the 120 -s groups. Within these constraints, on each day, the order of presentation of the stimuli and the time at which they were presented were determined randomly.

Following completion of training, the rats were reacclimated for 2 days in 1-h daily sessions to the test context with the lick tube in place. On the following day, the rats were tested. Each rat was placed in its test context, and after it drank for 5 cumulative seconds, licking was recorded for $5 \mathrm{~s}$ after which the CS was presented. Licking during the first $30 \mathrm{~s}$ of the CS was recorded using twelve 2.5 -s bins.

\section{Results}

As in Experiment 1, rats that took more than $1 \mathrm{~min}$ to complete 5 consecutive seconds of drinking were eliminated from the analysis. One animal in the 30-s-unpaired group met this criterion. The log-transformed latencies to complete 5 consecutive seconds of drinking immediately prior to CS onset were examined using an ANOVA with CS duration and the level of contingency between CS X and

Table 2 Design of Experiment 2

\begin{tabular}{|c|c|}
\hline Group & Training \\
\hline 30-s-Paired & $30-\mathrm{s} \mathrm{X}+/ 30-\mathrm{s} \mathrm{Y}-$ \\
\hline 120-s-Paired & $120-\mathrm{s} \mathrm{X}+/ 120-\mathrm{s} \mathrm{Y}-$ \\
\hline 30-s-Unpaired & 30-s X- / 30-s Y+ \\
\hline 120-s-Unpaired & $120-\mathrm{s}$ X- /120-s Y+ \\
\hline
\end{tabular}

$\mathrm{X}$ and $\mathrm{Y}$ were a complex tone or a white noise. + indicates footshock at the end of the CS; - after a letter (X or A) indicates nonreinforcement the US as factors. It failed to show any baseline differences between the groups, all $p \mathrm{~s}>.05$.

Figure 3 depicts the lick suppression ratio (computed as in Experiment 1) as a function of time in the CS, CS duration, and the level of contingency between CS X and the US. The CS duration effect observed in Experiment 1 did not appear here. The suppression ratio in the 30-spaired group was nearly identical to the suppression ratio in the 120-s-paired group. Moreover, although the suppression ratio data from the unpaired groups look noisier overall, there does not seem to be any difference between the paired and the unpaired groups. Critically, the reactive pattern, which was observed once more in the paired groups, was also observed in the unpaired groups. This impression was confirmed by a mixed-design ANOVA, using time in the CS, CS duration, and the level of contingency between CS X and the US as factors, which showed only a significant effect of time in the CS, F(11, $473)=8.51, p<.01$. Thus, we replicated the reactive pattern observed in Experiment 1 within the paired groups, and critically, the same pattern of behavior was observed in
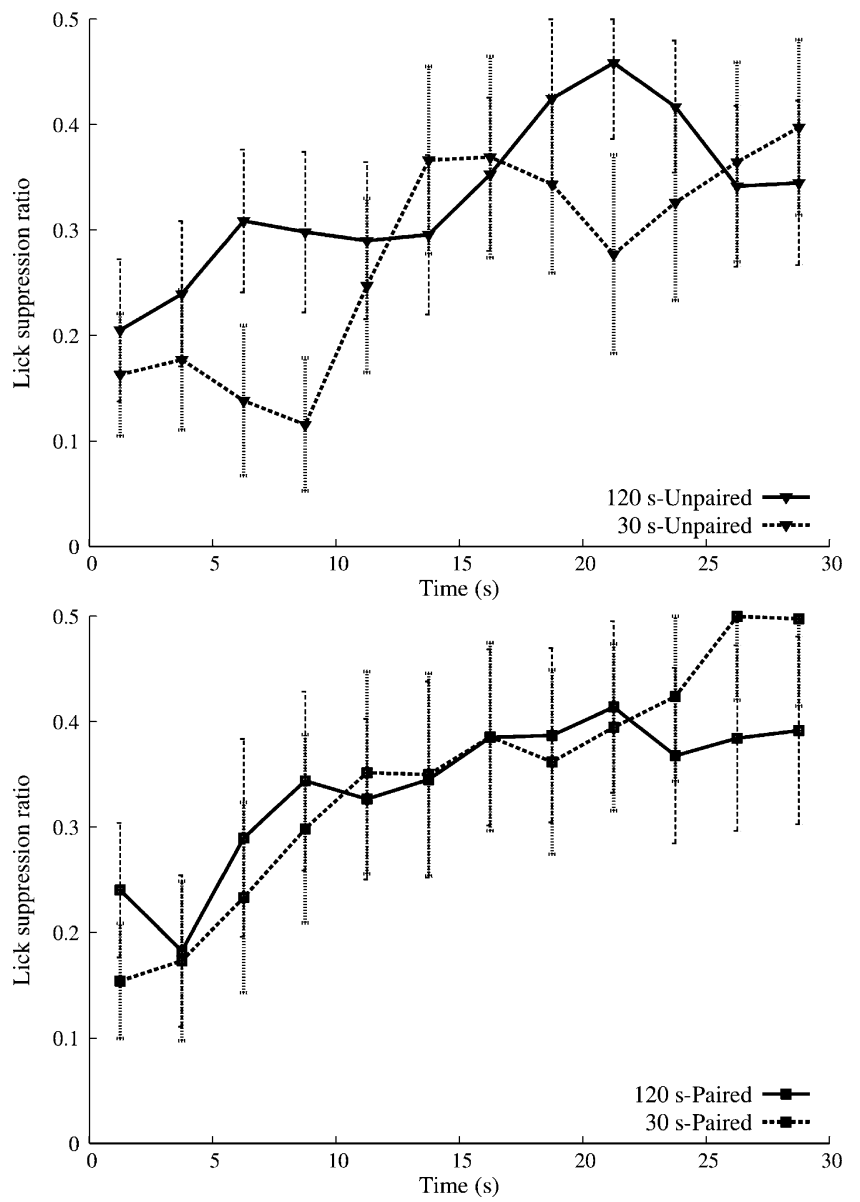

Fig. 3 Lick suppression ratio as a function of absolute time during the first $30 \mathrm{~s}$ of the $\mathrm{CS}$ as a function of number of trials and condition in Experiment 2. Bars represents standard errors 
the unpaired groups. This suggests that the reactive pattern of behavior reflects changes in nonassociative behavior (e.g., sensitization) across the duration of the test CS .

\section{Discussion}

In Experiment 2, we compared the temporal pattern of responding to a CS either paired or unpaired with a shock in groups, which had received overall the same level of shock exposure. Our goal was to establish whether the time-varying component of suppression identified in Experiment 1 was a CR due to the pairing of the CS with the US or an unconditioned change in the processing of stimuli in general, triggered by the mere exposure to the US. The data clearly argue in favor of the second hypothesis in that the reactive pattern observed in the paired groups in Experiment 1 was observed in both the paired and the unpaired groups in Experiment 2.

One could still rescue the idea that the reactive pattern is a CR by assuming that the fear generated by the paired CS generalized to the unpaired one. Although this is a plausible account, previous experiments in our laboratory have established that there is little stimulus generalization between a tone and a white noise. For instance, in Experiment 1 of Yin, Barnet, and Miller (1994), one group (SN) was exposed to reinforced presentations of a tone and tested with that tone and a white noise that had never been presented before or paired with the US (the tone was actually counterbalanced with a clicker sound for half of the animals). They showed strong suppression to the tone, but none to the white noise (Yin et al., 1994, Fig. 1).

Together, the lack of a CS duration effect and the absence of difference between the paired and unpaired groups argue that little conditioning to the CS took place, or if it did, it was not expressed behaviorally. Since the shock intensity cannot be faulted, since it was strong enough to generate fear to the CS in Experiment 1, at least in the 30-s CS groups, this is probably a consequence of the shorter ITI. Yet it is noteworthy that, despite this, the US still had an effect on responding to the CS. This is consistent with other data from our laboratory indicating that the magnitude of conditioned responding is relatively weak after large numbers (50) of trials (i.e., the overtraining effect; Urcelay, Witnauer, \& Miller, 2010). Moreover, overall levels of suppression were weak in the present studies, which is consistent with our interpretation of low levels of suppression as being due to overtraining.

\section{General Discussion}

In Experiment 1 and 2, we looked at the temporal pattern of responding in lick suppression. We observed that rats exposed to the US suppressed responding more at the beginning of the CS than at its end. Pairing the CS with the US did not influence this pattern of behavior, provided that the US was presented (Experiment 2).

Overall, these data argue that responding to a CS in conditioned suppression has at least two components: a conditioned, time-independent (except in the cases in which sufficient training occurs to produce inhibition of delay) component, caused by the pairing of the CS and the US, and an unconditioned reactive component, caused by mere exposure to the US. The effect of US exposure (Experiment 2) is consistent with the view that variations in nonassociative learning (habituation and sensitization) drive the unconditioned, reactive component. Exposure to intense stimuli (e.g., footshock) is known to induce sensitization, which explained both the difference between the paired and unpaired groups in Experiment 1 and the difference between the no-US group in Experiment 1 groups and the unpaired groups in Experiment 2. The present results suggest that a comprehensive model of suppression should include nontrivial associative (e.g., Sutton \& Barto, 1981) and nonassociative (Groves \& Thompson, 1970) learning mechanisms.

The present research is a powerful reminder of a lesson often forgotten by students of conditioning: Mere exposure to a US can influence responding to other stimuli in ways that might, mistakenly, suggest associative processes. It is also a cautionary tale for researchers who might be using dependent variables that might be affected by the reactive pattern. If only for this reason, further research is necessary to better understand the nature of this unconditioned component, as well as the processes underlying it and the variables that affect it. It is certainly not restricted to lick suppression, since, as we already noted before, both Rescorla (1968) and Bouton et al. (2008) observed it in a barpress suppression paradigm.

Could the reactive pattern account for the apparent temporal learning and integration observed in lick suppression by Miller and colleagues (e.g., Amundson \& Miller, 2008; Arcediano et al., 2003, 2005; Barnet et al., 1997; Blaisdell et al., 1998; Cole et al., 1995)? Since they used the same lick suppression procedure that we did, it is very likely that the same reactive pattern observed in this study was obtained by those authors. It would have impacted on the dependent variable they used to assess fear to the CS (amount of time to complete 5 consecutive seconds of drinking). But the lack of interaction between time in the CS and CS duration in Experiment 2 (see Fig. 2) makes it clear that, if the subjects have the same amount of US exposure, the reactive pattern alone cannot explain differences in the amount of suppression: There has to be a difference in the fear triggered by the stimuli in the first place. Hence, it is unlikely that the data from Miller and 
collaborators are an artifact due to the reactive pattern. Instead, as was claimed by these authors, they probably reflect genuine temporal learning.

Acknowledgments We would like to thank Joseph Alessandro, Eric Curtis, Mario Laborda, Bridget McConnell, Gonzalo Miguez, Cody Polack, Sarah Sterling, Yumu Tanaka, and Gonzalo Urcelay for comments on an earlier version of the manuscript. This work was supported by NIH Grant MH 033881. J. Jozefowiez is supported by the Fundação para a Ciência e a Tecnologia.

\section{References}

Amundson, J., \& Miller, R. R. (2008). CS-US temporal relations in blocking. Learning \& Behavior, 36, 92-103.

Arcediano, F., Escobar, M., \& Miller, R. R. (2003). Temporal integration and temporal backward associations in human and nonhuman subjects. Learning \& Behavior, 31, 242-256.

Arcediano, F., Escobar, M., \& Miller, R. R. (2005). Bidirectional associations in humans and rats. Journal of Experimental Psychology: Animal Behavior Processes, 31, 301-318.

Barnet, R. C., Cole, R. P., \& Miller, R. (1997). Temporal integration in second-order conditioning and sensory preconditioning. Animal Learning \& Behavior, 25, 221-233.

Blaisdell, A., Denniston, J. C., \& Miller, R. R. (1998). Temporal encoding as a determinant of overshadowing. Journal of Experimental Psychology: Animal Behavior Processes, 24, 7283.

Bouton, M. E., Frohardt, R. J., Sunsay, C., Waddell, J., \& Morris, R. W. (2008). Contextual control of inhibition with reinforcement: Adaptation and timing mechanisms. Journal of Experimental Psychology: Animal Behavior Processes, 34, 223-236.

Church, R. M. (2002). Temporal learning. In H. Pashler \& C. R. Gallistel (Eds.), Stevens' handbook of experimental psychology: Vol. 3. Learning, motivation, and emotion (3rd ed., pp. 365-393). New York: Wiley.

Cole, R. P., Barnet, R. C., \& Miller, R. R. (1995). Temporal encoding in trace conditioning. Animal Learning \& Behavior, 23, 144153.

Estes, W. K., \& Skinner, B. F. (1941). Some quantitative properties of anxiety. Journal of Experimental Psychology, 29, 390-400.

Gibbon, J., \& Balsam, P. D. (1981). Spreading associations in time. In C. M. Locurto, H. S. Terrace, \& J. Gibbon (Eds.), Autoshaping and conditioning theory (pp. 219-253). New York: Academic Press.
Groves, P. M., \& Thompson, R. F. (1970). Habituation: a dual-process theory. Psychological Review, 77, 419-450.

Hammond, L. J., \& Maser, J. (1970). Forgetting and conditioned suppression: role of a temporal discrimination. Journal of the Experimental Analysis of Behavior, 13, 333-338.

Hendry, D. P., \& Van-Toller, C. (1965). Alleviation of conditioned suppression. Journal of Comparative and Physiological Psychology, 59, 458-460.

Holmes, P. A., Jackson, D. E., \& Byrum, R. P. (1971). Acquisition and extinction of conditioned suppression under two training procedures. Learning and Motivation, 2, 334-340.

Labarbera, J. D., \& Church, R. M. (1974). Magnitude of fear as a function of expected time to an aversive event. Animal Learning \& Behavior, 2, 199-202.

Libby, M. E., \& Church, R. M. (1975). Fear gradients as a function of the temporal interval between signal and aversive event in the rat. Journal of Comparative and Physiological Psychology, 88, 911916.

Rescorla, R. A. (1968). Probability of shock in the presence and absence of CS in fear conditioning. Journal of Comparative and Physiological Psychology, 66, 1-5.

Rosas, J. M., \& Alonso, G. (1996). Temporal discrimination and forgetting and CS duration in conditioned suppression. Learning and Motivation, 27, 43-57.

Rosas, J. M., \& Alonso, G. (1997a). The effect of context change upon long-term memory of CS duration. Behavioural Processes, $39,69-76$

Rosas, J. M., \& Alonso, G. (1997b). Forgetting of the CS duration in rats: the role of retention interval and training level. Learning and Motivation, 28, 404-423.

Savastano, H. I., \& Miller, R. R. (1998). Time as content in Pavlovian conditioning. Behavioural Processes, 44, 147-162.

Schachtman, T. R., Channell, S., \& Hall, G. (1987). Effects of CS preexposure on inhibition of delay. Animal Learning \& Behavior, 51, 301-311.

Sutton, R. S., \& Barto, A. G. (1981). Toward a modern theory of adaptive networks: expectation and prediction. Psychological Review, 88, 135-140.

Urcelay, G. P., Witnauer, J. E., \& Miller, R. R. (2010). The role of context in performance decrement resulting from extended training. Manuscript submitted for publication.

Yin, H., Barnet, R. C., \& Miller, R. R. (1994). Second-order conditioning and Pavlovian conditioned inhibition: operational similarities and differences. Journal of Experimental Psychology: Animal Behavior Processes, 20, 419-428.

Zielinski, K. (1966). Inhibition of delay as a mechanism of the gradual weakening of the conditioned emotional response. Acta Biologiae Experimentalis, 26, 407-418. 